\title{
Smartphone Use, Experience of Learning Environment, and Academic Performance among University Students: A Descriptive Appraisal
}

\author{
Gabriel Faimau $\mathbb{D}^{\mathrm{D}}{ }^{1,2}$ Kelebogile Tlhowe, ${ }^{1}$ and Omphile Tlhaolang ${ }^{1}$ \\ ${ }^{1}$ Department of Sociology, University of Botswana, Gaborone, Botswana \\ ${ }^{2}$ Unit for Reformational Theology and the Development of the South African Society, North-West University, South Africa
}

Correspondence should be addressed to Gabriel Faimau; faimaug@ub.ac.bw

Received 15 October 2021; Accepted 20 January 2022; Published 10 February 2022

Academic Editor: Christos Troussas

Copyright (c) 2022 Gabriel Faimau et al. This is an open access article distributed under the Creative Commons Attribution License, which permits unrestricted use, distribution, and reproduction in any medium, provided the original work is properly cited.

\begin{abstract}
In our contemporary digital society, the smartphone is at the center of a powerful technological revolution affecting multiple domains. In the context of higher learning, the use of smartphones among students has been an area of interest. Previous studies on smartphone use and academic performance have generally focused on measuring the impact that smartphone use has on the academic performance of students. The purpose of this study is to examine the extent to which gender differences and the experience of a particular learning environment contributes to the use of smartphones for academic purposes. Data were collected through the use of a standardized self-report questionnaire completed by 300 first-year and 203 fourth-year undergraduate students from the University of Botswana. Our analysis is guided by the following specific objectives: first, to explore gender and the patterns of smartphone use for academic purposes; second, to appraise the contributing value of the experience of a learning environment on the use of smartphones to enhance academic achievement; and third, to examine smartphone use and its possible contribution to the performance outcome of students. Overall, we argue that the use of a smartphone for academic purposes is partly influenced by the extent to which a student is familiar with or understands the multiple contexts that shape his/her learning environment. For further studies in the field of smartphone use and academic performance, we suggest using multiple methods of data collection to uncover how students attach meanings to the use of smartphones and the role of smartphone use in improving their academic performance outcomes.
\end{abstract}

\section{Introduction}

The emergence of the multipurpose mobile computing device known as the smartphone has revolutionized our traditional social relationships and social networks. As of August 2020, the number of smartphone users worldwide has surpassed three billion [1]. The smartphone is at the center of a powerful technological revolution affecting multiple domains. In the context of higher learning, the use of smartphones among students has been an area of interest. Most previous studies have generally focused on smartphone addiction and its influence on students' quality of life [2-4]. Within this research area, scholarly studies have also been dedicated to examining the association between smartphone use and academic performance [5-10]. In this particular research field, previous studies revealed conflicting findings. Some studies raised the concern that the use of smartphones, particularly entertainment apps, has contributed to poor academic performance among students on the one hand $[8,11,12]$. At the same time, some found that the use of smartphones in classrooms enhances students' learning process and activities, as they use some features of the smartphone, such as a camera to capture the notes presented in class $[5,6]$. However, what is generally lacking is a detailed analysis of the experience of a student's learning and social environment and how this has contributed to the use of smartphones for academic purposes. The purpose of this study is to examine the extent to which gender differences 
and the experience of a particular learning environment contribute to the use of smartphones for academic purposes.

\section{Literature Review}

The explosion of smartphone use in higher education has been phenomenal in our contemporary digital society. As digital natives, students in institutions of higher learning cannot be separated from their smartphones. Recent reports revealed that, on average, young people, including students between the ages of 18 and 24 years, access and look at their smartphone 214 times a day and 1500 times in a week $[2,13]$. Given that digital natives are also learners, many educational apps have now been designed to meet students' needs [6]. In South Korea, a study by Han and Yi [7] found that approximately $99 \%$ of college students had adopted smartphones and that having a good smartphone with diversely interesting qualities was a trend among the students as it allows for many functions to be used anytime and anywhere.

The association of smartphone use and academic performance has generated interest among scholars, as demonstrated in the increasing number of scholarly studies in this field over the past decade. These studies, however, present conflicting results from different contexts. A review by Jumoke et al. [9], for example, showed that most of the research done so far revolved around a common concern that the use of mobile phones in academic institutions, including higher learning institutions, is problematic. Part of the problem is that mobile phones create a room to combine students' roles with other roles; thus, their use distracts and disrupts the students' academic work. With its flexibility, a smartphone allows for multitasking. In the context of smartphone use and how it contributes to student learning and academic performance, previous studies identified several popular activities among students: social networking, downloading course materials, reading course materials, reading and sending text messages while attending class, and contacting peers and lecturers for academic consultation. Based on an analysis of smartphone use among students for these activities, previous studies have identified smartphone use as a contributing factor to poor academic performance among students, as it decreases motivation to do academic work. Among others, it has been suggested that there are many entertainment apps and social media platforms that can disturb learning and encourage procrastination, such as watching videos, playing games, or texting $[5,14-16]$.

The association between smartphone use and poor academic performance is often attributed to smartphones' multitasking space. Rosen et al. [16] identified a link between smartphone multitasking and a decline in academic performance. A study conducted by Karpinski et al. [12] among college students in the USA also identified a negative relationship between the use of social networking sites and GPA, moderated by multitasking. Measuring smartphone use by the texting habits of students, Womack and McNamara [17] found that during a six-minute lecture, on average, students spend 2.69 minutes texting instead of focusing on the lesson. The same study indicated that students who were texting during the lecture performed $27 \%$ worse on a quiz than students who did not write any text messages. Additionally, continuous usage of the smartphone for chatting and social networking can lead to smartphone addiction, leading to low academic performance. While smartphones are equipped with many features that students can use to access any content, they require to improve their academic work, as in countries on other continents, studies on students in higher learning institutions in Africa continue to demonstrate an opposite expectation of improved academic performance among students. A study on the use of smartphones by university students in Tanzania, Kibona, and Mgaya [11] found an association between negative academic results and the use of smartphones, as the majority of students who used smartphones tend to achieve lower GPAs.

The media multitasking theory has been generally used as a lens through which the influence of smartphone use on students' academic performance is examined. As a conceptual model, Junco and Cotten ([18], pp. (505-6) defined multitasking as "divided attention and nonsequential task switching for ill-defined tasks as they are performed in learning situations." Mayer and Moreno [19] provide a cognitive theory of multimedia learning relevant to examining multitasking engagement and academic performance. They argue that human memory is limited in its ability to process information coming from multiple channels. This limitation means that meaningful learning requires a substantial amount of cognitive processing to allow learners to organize the learning materials in a coherent structure and integrate the same materials with their existing knowledge to create meaningful knowledge. Meaningful learning is defined as a "deep understanding" of the presented learning materials "reflected in the ability to apply what was taught to new situations" and use various problem-solving models in response to various existing and new novel problems (Mayer and Moreno, 2003, p. 43).

Consequently, when essential processing demands exceed the processing capacity, learners are presented and exposed to a "cognitive overload" condition with the potential of creating a "split attention effect" that, in turn, diminishes the meaningful learning process (Mayer and Moreno, 2003, p. 45). In a cognitive overload mode, multitaskers cannot perform effectively due to the multiple cognitive demands placed upon them simultaneously. In other words, multitasking weakens or damages performance outcomes [20]. A smartphone's presence brings about a new learning environment as it creates and presents a multitasking environment for learners or students. Multitasking is also about task switching. In this context, the multitasking environment brought about by a smartphone provides significant space for multiple task switching that can interrupt the learning process. Like the cognitive model presented earlier, frequent task switching that interrupts the learning process is often cited as a reason for prospective memory failure [21].

Scholarly studies have also underlined the positive contribution of smartphone use to the academic performance of students. A recent study in Spain found a strong association between the use of smartphones in educational centers and 
better academic results for students; it concludes that "as mobile phones have also become the main communication device, students who use a smartphone more frequently to learn are more likely to perceive and experience this positive impact on their academic performance" ([6], p. 7). The same finding was highlighted in the study of Ahmed et al. [5] as they concluded that although entertainment apps seem to damage the academic performance of students, generally smartphone applications, multimedia service message (MMS), short service message (SMS), and warp-speed processing have an affirmative and positive impact on the academic performance of students in universities. In the context of the United Arab Emirates, a study by Johnson and Radhakrishnan [22] revealed that students use smartphones to enhance their learning when they use features of the smartphone, such as a camera to capture notes presented in class. In a different context, Anshari et al. [15] assessed the possibility of having smartphone use as a powerful learning aid or a serious interference to learning in classrooms. Their study showed that smartphones' size and weight are advantageous features, making it convenient to access digital materials in a class and any other information that can be useful to students. As students can record or take videos of the lectures, they can also use the videos or captured notes later to study the content of the lectures and lecture materials.

Not all studies, however, confirm the association between smartphone use and academic performance. A recent study conducted in India among undergraduate medical students revealed that although one-fifth of the students suffered from smartphone addiction, the association between smartphone use and academic performance is inconclusive [14]. Similarly, a study conducted among schoolbased agricultural education students in Louisiana, the USA, suggested no significant difference in terms of academic performance between students who used smartphones and those who learned using printed materials [23]. Consequently, Gomes-Garcia et al. [6] suggested that the positive effect of smartphone use for academic purposes largely depends on the digital competency of a student or a learner. They confirmed that a digitally competent student is likely to obtain better academic results because a student's self-efficacy also influences the positive effect on academic performance in using mobile phones.

\section{Study Context and Objectives}

Studies that we have reviewed earlier generally focus on the link between smartphone use and students' academic performance. Detailed analysis of gender perspectives of smartphone use and how gender differences are associated with smartphone use for learning purposes are generally absent in previous studies on smartphone use and academic performance. Although the field of gender differences and smartphone use has attracted several scholarly studies, these studies focus on the gender preference of smartphone and smartphone use [24], the prevalence of smartphone addiction and factors associated with smartphone addiction in male and female students [25], and gender differences in the association of smartphone use with mental health [26].
Another dimension commonly neglected in the study of smartphone use for academic performance is the student's experience of the learning environment. The learning environment refers to circumstances and settings that provide space for the real-life application of knowledge [27]. The learning environment is also about multiple contexts and relationships that shape and facilitate a learner's engagement in the learning process [28]. While these settings and contexts vary, scholars suggest that the learning environment is normally determined by factors such as sociocognitive support (from teachers, parents, and peers), the learner's socialization of various academic regulations and requirements, the learner's psychological autonomy, healthy competition, and the meaningfulness of schoolwork [29]. These factors are normally influenced by the familiarity of a student with the culture of a higher learning institution, which can be translated to the number of years a student has spent in the institution. Experience of a particular learning environment assumes the knowledge, mental positioning, and disposition of a learner through the ability to navigate the various contexts and settings that shape the learning process. In the context of an institution of higher learning, the experience of a learning environment depends on the number of years a student has spent in that environment.

This study is generated from a study conducted in Botswana. While research on smartphone use in relation to the academic performance of students in Botswana is certainly limited, there is also a vital need to understand better the mechanisms that underpin the association between smartphone use and academic performance and how the technological advancement of the smartphone can be harnessed to make a genuine contribution to student learning [4]. A study by Lesitaokana [30] showed that smartphone use and subscriptions have increased over the years since the emergence of smartphones in Botswana about a decade ago. The increase in mobile subscriptions goes along with the increase in access and use of the Internet. Statistics from the Botswana Communications Regulatory Authority (BOCRA) revealed an increase in mobile broadband subscriptions from 1,404,065 in 2017 to $1,523,545$ in 2018 [31].

Our study focused on three overarching objectives based on our assessment of the research gap in the existing literature on the association of smartphone use with academic performance:

(1) To examine the gender differences in smartphone use for learning activities among students. In this context, we hypothesized an association between gender and the use of a smartphone for social networking, downloading and reading course materials, and contacting peers and lecturers for academic assistance.

(2) To appraise the contributing value of the experience of a learning environment with smartphone use in enhancing academic achievement. Here, we hypothesized an association between the year of study and the use of a smartphone for downloading and reading course materials and contacting peers and lecturers for learning purposes. 
(3) To investigate the contribution of smartphone use to the performance outcomes of students. Informed by this objective, we hypothesized an association between the use of a smartphone for downloading and reading course materials and the performance outcome of students in terms of grade point average (GPA).

Based on the above three overarching objectives, this article focuses on the following research questions:

(i) RQ1: In what ways do gender-related differences influence the use of smartphones for learning purposes?

(ii) RQ2: What is the contributing value of the experience in a particular learning environment in relation to smartphone use and academic performance?

RQ3: To what extent does smartphone use contribute to the performance outcomes of students?

\section{Methods}

A descriptive quantitative study design was adopted in this study, as it was concerned with describing the patterns of smartphone use among students in relation to their academic performance and the contribution of the experience of a learning environment to smartphone use for academic purposes. Descriptive research entails describing the characteristics of an individual or a group. Data for this study were collected through the administration of self-report questionnaires. The research questionnaire consisted of demographic variables, which refers to information about particular characteristics of participants and close-ended questions, limiting a respondent's response to the stated alternative responses [32].

This study involved 503 undergraduate students from the University of Botswana. As has been explained, the experience of a learning environment has been a neglected dimension in the study of smartphone use and academic performance. In response to this research gap, we added the experience of a learning environment as a dimension in the study design. To facilitate the measurement of this dimension, the selection of research participants for this study focused only on first-year and fourth-year undergraduate students. Informed by this approach, 300 first-year and 203 fourth-year undergraduate students from seven faculties were selected to participate in the study. First-year students were selected based on the assumption that they have just been exposed to a new learning environment, as they have just transitioned from secondary education to higher education settings.

Similarly, the fourth-year students were involved in the study because they have been long enough in a higher education setting and are familiar with the higher education system and its requirements. Respondents of the study were selected using a convenience sampling strategy, a type of nonprobability sampling in which participants are sampled simply because they are "convenient" sources of data for researchers [33]. Fieldwork for this study was carried out between March and April 2019. The participants were informed that their participation in the study was voluntary and that confidentiality and anonymity were observed and ensured. Participants' consent to participate in the study was obtained as part of the questionnaire.

\section{Results and Analysis}

This section presents the study findings guided by the study objectives, hypotheses, and research questions. Descriptive analysis was used to highlight the main features of the data and the key characteristics of the study participants. As such, the presentation of study findings utilizes frequency calculation or percentage distribution. Pearson's chi-square test was used to determine the association between some selected variables. The independent variables include gender and year of study. The dependent variables were the use of smartphones for social networking, downloading and reading course materials, and contacting peers and lecturers for academic assistance. We also examined the association between smartphone use and academic performance with downloading and reading course materials as independent variables and performance outcome in the form of cumulative grade point average (CGPA) as the dependent variable.

5.1. Characteristics and Distribution of Study Population. Table 1 provides the demographic characteristics and distribution of the study participants. As already indicated, this study's data were obtained from a sample of 503 students at the University of Botswana. The sample includes 300 (59.6\%) first-year students and 203 (40.4\%) fourth-year students. In terms of gender, 217 (43.1\%) participants were male and 286 (56.9\%) were female. Ages of the respondents ranged from 15 to $31+$ years, with most of the participants (52.3\%) falling within the range of 21-25 years, followed by the 15-20 years age range $(45.3 \%)$. The study participants were enrolled in different faculties, such as the faculty of social sciences with 138 (27.4\%) participants, faculty of business with 111 (22.1\%) participants, faculty of humanities with 77 (15.3\%) participants, faculty of engineering and technology with 73 (14.3\%) participants, faculty of science with $54(10.7 \%)$ participants, faculty of education with 36 (7.2\%) participants, and last, faculty of health sciences with $14(2.8 \%)$ participants. The choice of involving students from different academic programs was informed by the desire to get a broad picture of the phenomenon under study.

5.2. Gender and Smartphone Use. To assess smartphone use patterns among students in relation to their academic performance, this study identified several major uses of smartphones among students from the existing literature and previous scholarly studies. These uses include social networking, downloading and reading course materials, and contacting lecturers and classmates for academic purposes. These predefined aspects of smartphone use guide the questions stated in the self-report questionnaire. As such, we hypothesized that there is an association between gender and the use of smartphones for social networking, downloading 
TABle 1: Demographic characteristics of study participants.

\begin{tabular}{lcc}
\hline Gender & Frequency & Percentage \\
\hline Male & 217 & 43.1 \\
Female & 286 & 56.9 \\
Total & 503 & 100 \\
\hline Age & Frequency & Percentage \\
\hline $15-20$ years & 228 & 45.3 \\
$21-25$ years & 263 & 52.3 \\
$26-30$ years & 10 & 2.0 \\
$31+$ years & 2 & 0.4 \\
Total & 503 & 100 \\
\hline Year of study & Frequency & Percentage \\
\hline First year & 300 & 59.6 \\
Fourth year & 203 & 40.4 \\
Total & 503 & 100 \\
\hline
\end{tabular}

and reading course materials, and contacting peers and lecturers for learning purposes.

The use of smartphones for social networking through various social media and social networking platforms seems popular among students. This study found that among the study participants $(n=503), 87.5 \%$ of the students indicated using their smartphones for social networking. As far as gender is concerned, there is no significant difference between male and female participants, as $89.4 \%$ of male students and $86 \%$ of female students indicated that they used their smartphones for social networking. Pearson's chisquare test was performed to determine the association between gender and smartphone use for social networking. The test showed that there is no significant association between the two variables $(p>0.005)$. As such, we rejected the hypothesis that there is an association between gender and smartphone use for social networking.

Previous studies established that downloading and reading course materials are two main smartphone uses. As given in Table 2, in regard to these smartphone activities, $69.2 \%$ and $66.4 \%$ of the students indicated they used their smartphones to download and read the course materials, respectively. In comparison, female participants seemed to outnumber male participants by roughly $10 \%$ in terms of downloading and reading course materials using smartphones. Pearson's chi-square test confirmed a significant association between gender and downloading course materials $(p=0.010)$ and reading course materials using a smartphone $(p=0.021)$. In this case, we accepted the hypothesis that there is a significant association between gender and smartphone use for downloading and reading course materials.

Scholarly studies have established that students tend to use smartphones to contact their peers and lecturers for academic assistance. To assess the variables of using a smartphone to contact peers and lecturers for academic assistance, we adopted five answer options: "never," "rarely," "sometimes," "often," and "always." The study showed that in terms of contacting lecturers and peers for academic assistance, $33.6 \%$ of participants believed that they have "never" contacted their lecturers. Only $1.8 \%$ indicated that they have "never" contacted their peers for academic assistance. Similarly, $49.3 \%$ of students claimed that they "always" contacted their peers, while only $7.2 \%$ of participants contacted their lecturers for academic assistance using a smartphone. This finding demonstrated that, compared to their peers, students generally contacted their lecturers through smartphones only when their academic needs required them to do so or when their peers could not provide satisfactory responses to their academic queries. This finding cut across all respondents, regardless of gender. A statistical test confirmed this finding, as our Pearson's chi-square test demonstrated no significant difference between male and female participants in regard to contacting lecturers or peers for academic assistance ( $p=0.411)$. Therefore, we rejected the hypothesis that there is an association between gender and the use of smartphones for contacting peers and lecturers for academic assistance.

5.3. Year of Study and Smartphone Use. One of this study's major contributions is that it considers experience in a learning environment as a key dimension in analyzing the relationship between smartphone use and academic performance. In this study, experience in a learning environment is translated to the number of years a student has spent in the environment of a higher learning institution. The choice of having only first-year and fourth-year undergraduate students participating in this study is based on a basic assumption: the fourth-year undergraduate students are likely to have more experience in the university's learning environment than their first-year counterparts. Since both groups have different experiences within the learning environment of higher education, measuring how students use smartphones for academic purposes is likely to offer a new dimension to this research field. Therefore, we hypothesized that there is an association between the year of study and the use of smartphones for social networking, downloading and reading course materials, and contacting lecturers for academic assistance.

Table 3 provides a crosstabulation of smartphone use for social networking, downloading, and reading course materials by year of study. This study revealed that the use of smartphones to access social media platforms for social networking among first-year students outnumbered the fourth-year students by nearly $18 \%$, as $94.7 \%$ of first-year students confirmed their smartphone use for social networking 
TABLE 2: Crosstabulation of smartphone use for downloading and reading course materials self-rating by gender $(n=503)$.

\begin{tabular}{|c|c|c|c|}
\hline & & Male (\%) & Female (\%) \\
\hline \multirow{2}{*}{ Smartphone use for downloading course materials * } & No & 36.9 & 26.2 \\
\hline & Yes & 63.1 & 73.8 \\
\hline \multirow{2}{*}{ Smartphone use for reading course materials ${ }^{* *}$} & No & 39.2 & 29.4 \\
\hline & Yes & 60.8 & 70.6 \\
\hline
\end{tabular}

${ }^{*} P=0.010 .{ }^{* *} P=0.021$.

TABLE 3: Crosstabulation of smartphone use for social networking, downloading, and reading course materials self-rating by year of study $(n=503)$.

\begin{tabular}{|c|c|c|c|}
\hline & & $1^{\text {st }}$ year $(\%)$ & $4^{\text {th }}$ year $(\%)$ \\
\hline \multirow{2}{*}{ Smartphone use for social networking * } & No & 5.3 & 23.2 \\
\hline & Yes & 94.7 & 76.8 \\
\hline \multirow{2}{*}{ Smartphone use for downloading course materials ${ }^{* *}$} & No & 32.3 & 28.6 \\
\hline & Yes & 67.7 & 71.4 \\
\hline \multirow{2}{*}{ Smartphone use for reading course materials ${ }^{* * *}$} & No & 50.3 & 8.8 \\
\hline & Yes & 49.7 & 91.1 \\
\hline
\end{tabular}

${ }^{*} P=0.001 .{ }^{* *} P=0.370 .{ }^{* * * *} P=0.001$.

compared to $76.8 \%$ of fourth-year students. Pearson's chisquare test was performed to determine the association between smartphone use for social networking and the year of study. The test displayed a significant association between the two variables $(p=0.001)$. The hypothesis that there is an association between smartphone use for social networking and the year of study is accepted. This finding demonstrated that while students used smartphones for social networking, experienced students tend to pay more attention to learning activities other than accessing social media platforms for social networking compared to their first-year counterparts.

Relating to downloading course materials, this study found that there is not much difference between the first-year and fourth-year students, as $67.7 \%$ of first-year students and $71.4 \%$ of four-year students acknowledged that they used smartphones to download course materials. A chi-square test also confirmed no significant association between the year of study and downloading course materials using a smartphone $(p=0.370)$. In this case, we rejected the hypothesis that there is an association between smartphone use for downloading course materials and the level or year of study.

Unlike downloading course materials, the use of smartphones to read course materials seemed to be related to the level or year of study. Our study revealed that $91.1 \%$ of the fourth-year students did use a smartphone to read course materials. In comparison, only $49.7 \%$ of the first-year students used a smartphone for the same purpose. The Pearson chi-square test also suggested that, indeed, there is a significant association between the use of a smartphone to read course materials and the year of study $(p=0.001)$. This finding confirms the hypothesis that there is an association between using a smartphone to read course materials and the year of study. This is a significant finding as it demonstrated that experienced students (fourth-year students) tend to use various means available to them, including smartphones, to read their course materials compared to new students (firstyear students).
Familiarity with a learning environment is a contributing factor towards the frequency of contacting lecturers for academic assistance. In the context of this study, we asked if the year of study influences how students contacted their lecturers for academic assistance. The study found that when the year of study is considered, $24.1 \%$ of fourth-year students claimed that they "often" or "always" contacted their lecturers for academic assistance. In comparison, only $11.7 \%$ of first-year students provided the same response. Similarly, among those who stated that they "sometimes" contacted their lecturers for academic assistance, the percentage of fourth-year students outnumbers the first-year students by $16.5 \%$. Therefore, it can be concluded that experienced students (fourth-year students) tend to contact lecturers for academic assistance more than the new students (first-year students). In other words, the activity of contacting lecturers for academic assistance using a smartphone seemed to be influenced by the student's experience of a higher learning environment. A Pearson chi-square test was performed to determine the association between the year of study and smartphone use to contact lecturers for academic assistance. The test confirmed the association $(p=0.001)$. Therefore, we accepted the hypothesis that there is an association between the year of study and the use of a smartphone to contact lecturers for academic assistance.

5.4. Smartphone Use and Performance Outcome. One of the objectives that guided this study is related to how smartphone use contributed to students' academic performance outcome. To examine this, we focused on using smartphones for downloading and reading course materials and the performance outcome measured by the cumulative grade point average (CGPA). In this context, we hypothesized an association between downloading and reading course materials and CGPA. To facilitate the analysis, we compared smartphone use patterns and the current/recent CGPA 
obtained by students. At the University of Botswana, GPA is calculated using a scale of $0-5$. We categorized CGPA into four groups during the data collection process: "less than 2.6," "between 2.6 and 3.5," "between 3.6 and 4.5," and "between 4.6 and 5.0." From a total of 503 research participants, a majority of $53.5 \%$ and $31.2 \%$ revealed that their current/recent CGPA ranged between 2.6 and 3.5 and 3.6 and 4.5 , respectively. Only 17 students (3.4\%) stated that their current/recent CGPA ranged between 4.6 and 5.0. The remaining $11.9 \%$ or 60 students acknowledged that their current/recent CGPA was below 2.6.

Comparative analysis of the use of smartphones for social networking and CGPA showed that using a smartphone for social networking among students did not significantly influence the students' CGPA. The same result was obtained when the analysis focused only on those who indicated that they used their smartphones for social networking. This study's findings suggested that, in most cases, the use of a smartphone for social networking did not interrupt the specific time students normally allocated for selfstudy. Further study, however, is required to substantiate this suggestion.

Downloading and reading course materials using a smartphone are two common smartphone activities that are directly linked to students' performance outcomes. When the activity of using a smartphone for downloading course materials is directly compared to the CGPA variable, the results showed that there was no significant difference in terms of the obtained CGPA among those who claimed that they used a smartphone to download course materials and those who did not. For example, among those who indicated that they did not use a smartphone for downloading course materials, $51 \%$ and $32.9 \%$ stated that their current $/$ recent CGPA was within the categories of $2.6-3.5$ and 3.6-4.5, respectively. The study revealed similar findings for those who indicated that they used a smartphone for downloading course materials, with $54.6 \%$ and $30.5 \%$ having a current/ recent CGPA within the categories of 2.6-3.5 and 3.6-4.5, respectively. Pearson's chi-square test revealed no significant association between the use of a smartphone for downloading course materials and CGPA $(p=0.642)$. As such, we rejected the hypothesis that there is an association between using a smartphone to download course materials and CGPA.

A majority (66.4\%) of the study participants stated that they used a smartphone to read course materials. Among this subgroup, $37.6 \%$ and $21.7 \%$ stated that their current/ recent CGPA was within the categories of 2.6-3.5 and $3.6-4.5$, respectively. Within the same group, $5.4 \%$ obtained a CGPA of less than 2.6, while a minority of $1.8 \%$ obtained between 4.6 and 5.0. Logically, however, a high CGPA should be expected among those who dedicated time to reading course materials, including reading course materials using a smartphone. Considering the difference in intellectual capacity among students, this logical proposition can be substantiated when the probability distribution of the CGPA is taken into account. A comparative analysis revealed that those who used a smartphone to read the course materials seemed to perform better than those who did not. For example, among those who achieved a CGPA between 2.6 and 3.5 (269 participants), those who used a smartphone to read course materials outnumbered those who did not by nearly $10 \%$. Similar results were displayed within the CGPA category of 3.6-4.5 (157 participants), as those who used a smartphone to read course materials outnumbered those who did not by more than $4 \%$.

Interestingly, the same trend can be observed in the CGPA category of less than 2.6 (60 participants). In this category, those who did not use a smartphone for reading course materials outnumbered those who used a smartphone for a similar purpose by more than $10 \%$. These findings, therefore, suggest that to a certain degree, the use of a smartphone to read course materials contributes positively to the CGPA outcomes. Pearson's chi-square test confirmed a significant association between smartphone use for reading course materials and CGPA $(p=0.001)$. Therefore, we accepted the hypothesis that there is a significant association between smartphone use for reading course materials and the performance outcome of students.

\section{Discussion}

Among many activities that smartphone users engage in, social networking has been the most popular among students in previous studies $[10,34,35]$. Our study confirmed previous study findings, as it revealed that $87.5 \%$ of 503 students who participated in the study used their smartphones for social networking. Smartphones are equipped with advanced technological innovations that incorporate social media platforms in a single device. While there might be a gender difference in the practical use of social networking sites [35], in general, as this study revealed, there is no significant association between gender and the use of a smartphone to access social networking sites among students. For analysis purposes, however, what is probably more interesting is examining why young people use smartphones for social networking purposes. A recent survey conducted by the Pew Research Center [36] showed that young people and people with a higher education level are likely to use smartphones. Among others, the survey also found widespread use of social media platforms among smartphone users. One of the reasons why social networking sites are becoming more popular with the advent of smartphone technology is that a smartphone provides mobile connections that fuel persistent online activities, including activities on various social media platforms [37]. When exploring why young people use social networking sites, Shapiro and Margolin ([38], p. 1) suggest that young people value opportunities to "stay in touch with friends, make plans, get to know people better, and present oneself to others."

This study represents a new approach and contribution in the study of smartphone use and academic performance by incorporating the experience of a learning environment as an analytical dimension in this study field using the level or year of study as a variable. As the results showed, experienced students (fourth-year students) tend to use smartphones to read course materials and contact lecturers 
TABLE 4: Summary of hypotheses and study results.

\begin{tabular}{|c|c|c|}
\hline Hypotheses & Key findings & Results \\
\hline $\begin{array}{l}\text { 1. Gender and smartphone use: } \\
\text { (i) Hypothesis 1: there is an association } \\
\text { between gender and the use of a } \\
\text { smartphone for social networking. }\end{array}$ & $\begin{array}{l}\text { (i) More than } 89 \% \text { of male students and } 86 \% \\
\text { of female students use their smartphones for } \\
\text { social networking. }\end{array}$ & $\begin{array}{l}\text { (i) Hypothesis } 1 \text { is rejected as there is no } \\
\text { significant association between gender and } \\
\text { smartphone use for social networking. }\end{array}$ \\
\hline $\begin{array}{l}\text { (ii) Hypothesis 2: there is an association } \\
\text { between gender and smartphone use for } \\
\text { downloading and reading course materials. }\end{array}$ & $\begin{array}{l}\text { (ii) Female students outnumbered male } \\
\text { students by roughly ten percent in terms of } \\
\text { using smartphones to download and read } \\
\text { course materials. }\end{array}$ & $\begin{array}{l}\text { (ii) Hypothesis } 2 \text { is accepted as there is a } \\
\text { significant association between gender and } \\
\text { smartphone use for downloading and } \\
\text { reading course materials. }\end{array}$ \\
\hline $\begin{array}{l}\text { (iii) Hypothesis 3: there is an association } \\
\text { between gender and smartphone use for } \\
\text { contacting peers and lecturers for academic } \\
\text { assistance. }\end{array}$ & $\begin{array}{l}\text { (iii) Students contacted their lecturers } \\
\text { through smartphones only when their } \\
\text { academic needs required them to do so or } \\
\text { when their peers could not provide } \\
\text { satisfactory responses to their academic } \\
\text { queries. }\end{array}$ & $\begin{array}{l}\text { (iii) Hypothesis } 3 \text { is rejected as there is no } \\
\text { significant difference between male and } \\
\text { female students in regard to contacting } \\
\text { lecturers or peers for academic assistance }\end{array}$ \\
\hline $\begin{array}{l}\text { 2. Year of study and smartphone use: } \\
\text { (i) Hypothesis } 4 \text { : there is an association } \\
\text { between the year of study and the } \\
\text { smartphone use for social networking. }\end{array}$ & $\begin{array}{l}\text { (i) First-year students outnumbered the final } \\
\text { year students by nearly } 18 \% \text { in terms of } \\
\text { smartphone use for social networking. }\end{array}$ & $\begin{array}{l}\text { (i) Hypothesis } 4 \text { is accepted as there is a } \\
\text { significant association between the year of } \\
\text { study and smartphone use for social } \\
\text { networking. }\end{array}$ \\
\hline $\begin{array}{l}\text { (ii) Hypothesis } 5 \text { : there is an association } \\
\text { between the year of study and smartphone } \\
\text { use for reading course materials. }\end{array}$ & $\begin{array}{l}\text { (ii) More than } 91 \% \text { of the final year students } \\
\text { used smartphones to read course materials. } \\
\text { Only } 49.7 \% \text { of first-year students used } \\
\text { smartphones for the same purpose. }\end{array}$ & $\begin{array}{l}\text { (ii) Hypothesis } 5 \text { is accepted as there is an } \\
\text { association between the year of study and } \\
\text { smartphone use for reading course } \\
\text { materials. }\end{array}$ \\
\hline $\begin{array}{l}\text { (iii) Hypothesis 6: there is an association } \\
\text { between the year of study and smartphone } \\
\text { use for contacting lecturers for academic } \\
\text { assistance. }\end{array}$ & $\begin{array}{l}\text { (iii) Experienced students (final year) tend } \\
\text { to contact lecturers for academic assistance } \\
\text { more than the first-year students. }\end{array}$ & $\begin{array}{l}\text { (iii) Hypothesis } 6 \text { is accepted as there is an } \\
\text { association between year of study and } \\
\text { smartphone use tor contacting lecturers for } \\
\text { academic assistance. }\end{array}$ \\
\hline $\begin{array}{l}\text { 3. Smartphone use and performance } \\
\text { outcome: } \\
\text { (i) Hypothesis 7: there is an association } \\
\text { between reading course materials using } \\
\text { smartphones and performance outcome } \\
\text { (CGPA) }\end{array}$ & $\begin{array}{l}\text { (i) Students who used smartphones for } \\
\text { reading course materials seemed to perform } \\
\text { better than those who did not. }\end{array}$ & $\begin{array}{l}\text { (i) Hypothesis } 7 \text { is accepted as there is a } \\
\text { significant association between smartphone } \\
\text { use for reading course materials and the } \\
\text { performance outcome of students. }\end{array}$ \\
\hline
\end{tabular}

for academic assistance more than their first-year counterparts. Therefore, it could be argued that the use of a smartphone for academic purposes, including the improvement of performance outcomes, is partly influenced by the extent to which a student is familiar with or understands the multiple contexts that shape his/her learning environment. This argument goes along with the common suggestion that the learning environment facilitates the organizational arrangement of learning and an interactive learning process, which, in turn, enhances and maximizes the learner's commitment and performance [39].

Reading course materials is one of the main activities in the learning process. As smartphones emerged, new avenues for students to access learning materials were created. As this study indicated, downloading and reading course materials on smartphones are the two main popular uses of smartphones among students. This finding ties in with the studies conducted by Woodcock et al. [40] and Dukic et al. [41]. They found that students commonly consider smartphones as very useful devices for their academic work, as the devices provide them with access to course materials, library catalogues, note-taking, and discussion with peers concerning their course assignments. However, this study presents a salient finding relating to gender and access to course materials using smartphones, as it found that female students tend to outnumber their male counterparts in terms of downloading and reading course materials using smartphones. The literature search could not find previous studies that examined gender differences in connection to using a smartphone to access academic resources. While previous studies only noted a gender difference concerning the use of social networking sites [35], our study findings could be linked to the construction of academic motivation. For example, when investigating gender differences in connection with academic motivation and classroom behavior, previous studies found that compared to their male counterparts, female students generally have a higher level of academic motivation and behavioral engagement in their academic work [42, 43].

While multitasking using a smartphone is evident through the use of a smartphone for social networking and academic activities, this study underlines the insight that smartphones are indeed useful for learning, as they facilitate alternative ways for accessing and reading course materials, contacting lecturers for assistance, and discussing course assignments with peers [41]. However, a smartphone's direct influence on the level of academic performance outcome in terms of cumulative grade point average (CGPA) seems to be circumstantial, as this study demonstrated. This is to say that while smartphone use may contribute directly or indirectly to student academic performance, generally, factors contributing to academic performance outcomes vary. Among 
others, this includes learning styles and academic belief systems or confidence, support systems and learning environments, socioeconomic factors and student commitment, and student academic goals [44-46].

\section{Conclusion}

This study focused on examining the gender and patterns of smartphone use for academic purposes, appraising the contributing value of the experience of a learning environment to smartphone use for academic purposes and examining the extent to which smartphone use contributes to students' performance outcomes. Table 4 provides a summary of the study hypotheses and study findings.

The first research question (RQ 1) of this study interrogates the ways in which gender-related differences influence the use of smartphones for learning purposes. The use of a smartphone for social networking is popular among students, as this study revealed that $87.5 \%$ of the study participants used their smartphones for social networking. As far as gender is concerned, there is no significant difference between male and female participants, as $89.4 \%$ of male students and $86 \%$ of female students indicated that they use their smartphones for social networking. The demonstration of students' multitasking behavior can be seen in smartphones' use to access networking sites and course materials. This study presents a salient finding relating to gender and access course materials using smartphones. It found that female students tend to outnumber their male counterparts in terms of downloading and reading course materials using smartphones. This practice could be attributed to the construction of academic motivation, as previous studies suggested that compared to their male counterparts, female students generally have a higher level of academic motivation and behavioral engagement in their academic work.

This study also represents a new approach in the study field of smartphone use and academic performance by incorporating the experience of a learning environment as an analytical dimension. The second research question RQ (2) focuses on the experience in a learning environment and how it influences smartphone use for learning activities. In this study, experience in a learning environment is translated to the number of years a student has spent in the environment of a higher learning institution. As the results demonstrated, experienced students (fourth-year students) tend to use smartphones for reading course materials, reading and/or sending text messages while attending a class session, and contacting lecturers for academic assistance, more than the first-year students. Therefore, we argue that the use of a smartphone for academic purposes is partly influenced by the extent to which a student is familiar with or understands the multiple contexts that shape his/her learning environment.

The third research question (RQ 3) examines the extent to which smartphone use contributes to the performance outcomes of students. Comparative analysis of smartphone use and the cumulative grade point average (CGPA) shows that to a certain degree, the use of smartphones to read course materials contributes positively to the performance outcomes of the students. This study therefore underlines the insight that smartphones are useful for learning purposes, as they facilitate alternative ways for accessing and reading course materials and contribute directly or indirectly to the performance outcomes of students.

The study has several limitations. Since a self-report questionnaire was used to collect data, the interpretation of the study results was performed based on the assumption that the participants provided honest and reliable answers. Additionally, the study used a single method of data collection. While the questions included in the self-report questionnaire covered the study objectives, the opportunity to ask further questions beyond the questions written in the questionnaire was not available. In other words, using a single method of data collection, a self-report questionnaire, limits the possibility of engaging participants in an in-depth discussion relating to the research questions. For further studies of smartphone use and academic performance, we suggest using multiple methods of data collection, including in-depth interviews, to uncover how students attached meanings to the use of smartphones and the role of smartphone use in improving their academic performance outcomes.

\section{Data Availability}

The data used to support the findings of this study are available from the corresponding author upon request.

\section{Conflicts of Interest}

The authors declare that they have no conflicts of interest.

\section{Authors' Contributions}

G F., K T., and O M. conceptualized the study, developed methodology, performed formal analysis, visualized data, and reviewed and edited the article. $\mathrm{K} \mathrm{T}$. and $\mathrm{O} \mathrm{M}$. collected data. G F verified data. All authors have read and agreed to the published version of the manuscript.

\section{Acknowledgments}

Data collection for this research was funded by the Department of Tertiary Education Financing (DTEF), Government of the Republic of Botswana.

\section{References}

[1] S. O’Dea, Smartphone Users Worldwide 2016-2021. Statista, https:/www.statista.com/statistics/330695/number-of-smartphone-users-worldwide/, accessed on September 23, 2020, 2020.

[2] C. Eichenberg, M. Schott, and A. Schroiff, "Comparison of students with and without problematic smartphone use in light of attachment style," Frontiers in Psychiatry, vol. 10, pp. 1-6, Article ID 681, 2019.

[3] J. Li, A. Lepp, and J. E. Barkley, "Locus of control and cell phone use: implications for sleep quality, academic 
performance, and subjective well-being," Computers in $\mathrm{Hu}$ man Behavior, vol. 52, pp. 450-457, 2015.

[4] A. Lepp, J. E. Barkley, and A. C. Karpinski, "The relationship between cell phone use, academic performance, anxiety, and Satisfaction with Life in college students," Computers in Human Behavior, vol. 31, no. 1, pp. 343-350, 2014.

[5] R. R. Ahmed, F. Salman, S. A. Malik, D. Streimikiene, R. H. Soomro, and M. H. Pahi, "Smartphone use and academic performance of university students: a mediation and moderation analysis," Sustainability, vol. 12, no. 1, pp. 1-28, Article ID 439, 2020.

[6] M. Gómez-García, R. Soto-Varela, J. A. Morón-Marchena, and M. J. del Pino-Espejo, "Using mobile devices for educational purposes in compulsory secondary education to improve student's learning achievements," Sustainability, vol. 12, no. 9, pp. 1-12, Article ID 3724, 2020.

[7] S. Han and Y. J. Yi, "How does the smartphone usage of college students affect academic performance?" Journal of Computer Assisted Learning, vol. 35, no. 1, pp. 13-22, 2018.

[8] S. F. Ng, N. S. Hassan, N. H. Nor, and N. A. Malek, "The relationship between smartphone use and academic performance: a case of students in A Malaysian tertiary institution," Malaysian Online Journal of Educational Technology, vol. 5, no. 4, pp. 58-70, 2017, https://files.eric.ed.gov/fulltext/ EJ1156718.pdf.

[9] S. Jumoke, S. A. Oloruntoba, and O. Blessing, "Analysis of mobile phone impact on student academic performance in tertiary institution," International Journal of Emerging Technology and Advanced Engineering, vol. 5, no. 1, pp. 361-367, 2015, https://www.researchgate.net/publication/308412938_ Analysis_of_Mobile_Phone_Impact_on_Student_Academic_ Performance_in_Tertiary_Institution.

[10] G. H. Ezeah, C. E. Asogwa, and I. O. Edogor, "Social media use among students of universities in south-east Nigeria," IOSR Journal of Humanities and Social Science, vol. 16, no. 3, pp. 23-32, 2013.

[11] L. Kibona and G. Mgaya, “Smartphones' effects on academic performance of higher learning students: a case of ruaha catholic university - iringa, Tanzania," Journal of Multidisciplinary Engineering Science and Technology, vol. 2, no. 4, pp. 777-784, 2015, https://www.jmest.org/wp-content/uploads/JMESTN42350643.pdf.

[12] A. C. Karpinski, P. A. Kirschner, I. Ozer, J. A. Mellott, and P. Ochwo, "An exploration of social networking site use, multitasking, and academic performance among United States and European university students," Computers in Human Behavior, vol. 29, no. 3, pp. 1182-1192, 2013.

[13] H. Scholz, Study: We Use Our Smartphones 1500 Times a week Mobile Zeitgeist, https://www.mobile-zeitgeist.com/studiewir-nutzen-unsere-smartphones-1-500-mal-pro-woche/, accessed on 30 November 2020, 2017.

[14] R. M. Oswal, S. Pal, S. V. Patel, A. Patel, V. Doshi, and R. R. Gandhi, "Smartphone addiction among undergraduate medical students and its association with academic performance," Open Journal of Psychiatry \& Allied Sciences, vol. 11, no. 2, pp. 111-116, 2020.

[15] M. Anshari, M. N. Almunawar, M. Shahrill, D. K. Wicaksono, and M. Huda, "Smartphones usage in the classrooms: learning aid or interference?" Education and Information Technologies, vol. 22, no. 6, pp. 3063-3079, 2017.

[16] L. D. Rosen, K. Whaling, L. M. Carrier, N. A. Cheever, and J. Rokkum, "The media and technology usage and attitudes scale: an empirical investigation," Computers in Human Behavior, vol. 29, no. 6, pp. 2501-2511, 2013.
[17] C. L. Womack and J. M. McNamara, "Cell phone use and its effects on undergraduate academic performance," The Kennesaw Journal of Undergraduate Research, vol. 5, no. 1, pp. 1-9, 2017.

[18] R. Junco and S. R. Cotten, "No A 4 U: the relationship between multitasking and academic performance," Computers \& Education, vol. 59, no. 2, pp. 505-514, 2012.

[19] R. E. Mayer and R. Moreno, "Nine ways to reduce cognitive load in multimedia learning," Educational Psychologist, vol. 38, no. 1, pp. 43-52, 2003.

[20] M. Irwin and Z. Wang, "Multitasking," in Emerging Trends in the Social and Behavioral Sciences: Interdisciplinary Perspectives, R. A. Scott and S. M. Kosslyn, Eds., Wiley Blackwell, Oxford, 2015.

[21] M. Czerwinski, E. Horvitz, and S. Wilhite, "A diary study of task switching and interruptions," in Proceedings of the SIGCHI Conference on Human Factors in Computing Systems (CHI'04), Vienna, Austria, April 2004.

[22] S. Johnson and N. Radhakrishnan, "Academic use of smart phones among the students of business schools in uae - a study," Journal of Library and Information Management, vol. 4, no. 1, pp. 31-36, 2017, http://www.publishingindia.com/kjlim/97/academic-use-of-smart-phonesamong-the-students-of-business-schools-in-uae-a-study/ $546 / 3898 /$.

[23] H. E. Smith, J. J. Blackburn, K. Stair, and M. Burnett, "Assessing the effects of the smartphone as a learning tool on the academic achievement of school-based agricultural education students in Louisiana," Journal of Agricultural Education, vol. 59, no. 4, pp. 270-285, 2018.

[24] N. Ameen, R. Willis, and M. Hussain Shah, "An examination of the gender gap in smartphone adoption and use in Arab countries: a cross-national study," Computers in Human Behavior, vol. 89, pp. 148-162, 2018.

[25] B. Chen, F. Liu, S. Ding, X. Ying, L. Wang, and Y. Wen, "Gender differences in factors associated with smartphone addiction: a cross-sectional study among medical college students," BMC Psychiatry, vol. 17, no. 1, pp. 1-9, Article ID 341, 2017.

[26] S.-Y. Yang, C.-Y. Lin, Y.-C. Huang, and J.-H. Chang, "Gender differences in the association of smartphone use with the vitality and mental health of adolescent students," Journal of American College Health, vol. 66, no. 7, pp. 693-701, 2018.

[27] B. Paddison and C. Mortimer, "Authenticating the learning environment," Journal of Teaching in Travel \& Tourism, vol. 16, no. 4, pp. 331-350, 2016.

[28] D. J. Shernoff, Optimal Learning Environments to Promote Student Engagement, Springer, New York, 2013.

[29] E. Thuen, E. Bru, and T. Ogden, "Coping styles, learning environment and emotional and behavioural problems," Scandinavian Journal of Educational Research, vol. 51, no. 4, pp. 347-368, 2007.

[30] W. Lesitaokana, "Young people and mobile phone technology in Botswana," in Handbook of Children and Youth Studies, J. Wyn and H. Cahill, Eds., , pp. 1-11, Springer, 2014.

[31] BOCRA, BOCRA Annual Report, Botswana Communication Regulatory Authority, Gaborone, 2018.

[32] C. R. Kothari, Research Methodology: Methods and Techniques, New Age International, New Delhi, 2 edition, 2004.

[33] M. Battaglia, "Convenience sampling," in Encyclopedia of Survey Research Methodshttps://dx.doi.org/10.4135/ 9781412963947.n105, p. 149, Sage, Thousand Oaks, 2011, . 
[34] S. Fernandez, "University student's perspectives on using cell phones in classrooms - are they dialing up disaster?" The Turkish Online Journal of Educational Technology, vol. 17, no. 1, pp. 246-258, 2018, https://files.eric.ed.gov/fulltext/ EJ1165729.pdf.

[35] L. Gray, "Exploring how and why young people use social networking sites," Educational Psychology in Practice, vol. 34, no. 2, pp. 175-194, 2018.

[36] L. Silver, Mobile Connectivity in Emerging Economies, Pew Research Center, Washington, 2019, https://www.pewresearch.org/internet/2019/03/07/mobile-connectivity-inemerging-economies/.

[37] M. Anderson and J. Jiang, Teens, Social Media and Technology 2018, Pew Research Center, Washington, 2018.

[38] L. A. Spies Shapiro and G. Margolin, "Growing up wired: social networking sites and adolescent psychosocial development," Clinical Child and Family Psychology Review, vol. 17, no. 1, pp. 1-18, 2014.

[39] R. S. Vosko and R. Hiemstra, "The adult learning environment: importance of physical features," International Journal of Lifelong Education, vol. 7, no. 3, pp. 185-195, 1988.

[40] B. Woodcock, A. Middleton, and A. Nortcliffe, "Considering the Smartphone Learner: developing innovation to investigate the opportunities for students and their interest," Student Engagement and Experience Journal, vol. 1, no. 1, pp. 1-15, 2012.

[41] Z. Dukic, D. K. W. Chiu, and P. Lo, "How useful are smartphones for learning? Perceptions and practices of $\mathrm{Li}$ brary and Information Science students from Hong Kong and Japan," Library Hi Tech, vol. 33, no. 4, pp. 545-561, 2015.

[42] E. Skinner, C. Furrer, G. Marchand, and T. Kindermann, "Engagement and disaffection in the classroom: Part of a larger motivational dynamic?" Journal of Educational Psychology, vol. 100, no. 4, pp. 765-781, 2008.

[43] M. Bugler, S. P. McGeown, and H. St Clair-Thompson, "Gender differences in adolescents' academic motivation and classroom behaviour," Educational Psychology, vol. 35, no. 5, pp. 541-556, 2015.

[44] S. Cassidy and P. Eachus, "Learning style, academic belief systems, self-report student proficiency and academic achievement in higher education," Educational Psychology, vol. 20, no. 3, pp. 307-322, 2000.

[45] G. Crisp, A. Taggart, and A. Nora, "Undergraduate latina/o students," Review of Educational Research, vol. 85, no. 2, pp. 249-274, 2015.

[46] M. Ngoma, P. D. Ntale, and E. Abaho, "Social-economic factors, student factors, student academic goals and performance of students in institutions of higher learning in Uganda," Africa Education Review, vol. 14, no. 2, pp. 106-121, 2017. 